\title{
Alojamiento individual o en parejas: efecto sobre el consumo de alimento balanceado y el crecimiento en terneras Jersey
}

\author{
Jorge Alberto Elizondo-Salazar ${ }^{1} \bowtie$, Cynthia Rebeca Monge-Rojas ${ }^{1}$
}

1 Facultad de Ciencias Agroalimentarias. Estación Experimental Alfredo Volio Mata, Universidad de Costa Rica. Email: jorge.elizondosalazar@ucr.ac.cr, cynthia.mongerojas@ucr.ac.cr

El experimento se llevó a cabo en la Estación Experimental Alfredo Volio Mata de la Universidad de Costa Rica, con el objetivo de evaluar el efecto que tiene el alojamiento individual o en parejas sobre el consumo de alimento balanceado y los parámetros de crecimiento en terneras de la raza Jersey desde el nacimiento hasta el destete. Se utilizaron 20 terneras que se alojaron en cuadras, 10 de ellas permanecieron individualmente y las otras 10 se alojaron en parejas. Las terneras consumieron 4 litros de leche diarios y tuvieron libre acceso al alimento balanceado. No se encontraron diferencias significativas $(\mathrm{P}>0.05)$ en el consumo de alimento, donde para la semana uno fue de 0.132 y $0.052 \mathrm{~kg}$ para el tratamiento uno y dos, respectivamente. En la semana cuatro el consumo fue de $0.841 \mathrm{~kg}$ para los animales alojados individualmente y de $0.540 \mathrm{~kg}$ para las alojadas en parejas, en la semana ocho el consumo había aumentado gradualmente a 3.796 y $3.688 \mathrm{~kg}$ para el tratamiento uno y dos, y al final del experimento los animales estaban consumiendo 7.453 y $7.378 \mathrm{~kg}$, respectivamente. Con referencia al peso de los animales, se encontraron diferencias significativas $(\mathrm{P}<0.05)$ entre los tratamientos a partir de la semana 5 y hasta el final del experimento, donde los animales alojados individualmente presentaron pesos superiores a los animales alojados en parejas. El peso promedio de los animales en la semana 12 fue 78.20 y $72.50 \mathrm{~kg}$ para el tratamiento uno y dos, respectivamente. No se encontraron diferencias significativas entre tratamientos con respecto a parámetros de crecimiento como altura a la cruz, altura a la cadera o circunferencia torácica. Los resultados indican que el alojamiento en parejas no influyó sobre el consumo de alimento; sin embargo, los animales alojados individualmente obtuvieron mayores pesos en la etapa pre destete, situación que pudo deberse a que los animales alojados en parejas presentaron mayores episodios de enfermedades.

凶 Autor para correspondencia Jorge Alberto Elizondo-Salazar: jorge.elizondosalazar@ucr.ac.cr 